\title{
A computer program to synthesize American Sign Language
}

\author{
MICHAEL SHANTZ \\ De Anza Systems, Inc., San Jose, California 95131 \\ and \\ HOWARD POIZNER \\ Salk Institute for Biological Studies, La Jolla, California 92138
}

\begin{abstract}
A program is described that allows experimenters to generate American Sign Language forms by computer. The computer synthesis of such signs could allow major advances in the experimental investigation of the perception of sign language, much as computer-generated speech has done for the study of speech perception.
\end{abstract}

American Sign Language (ASL) is passed down from one generation of deaf people to the next as an autonomous and native language (Klima \& Bellugi, 1979; Lane \& Grosjean, 1980). As a visual language, ASL utilizes dimensions of space and movement to transmit information simultaneously about several spatial parameters. These parameters include the configuration of the hands, the location of the hands, and movement of the hands and arms. Strikingly, the key to the grammar of the language lies in large part in processes conveyed by particular patterns of movement and spatial contouring (Klima \& Bellugi, 1979), processes having psychological as well as linguistic significance (Poizner, Newkirk, Bellugi, \& Klima, 1981). That movement information alone is sufficient to convey these processes has been demonstrated by presenting sign forms as patterns of moving points of light, following Johansson's $(1973,1975)$ classic procedures for isolating biological motion (Poizner, Bellugi, \& Lutes-Driscoll, 1981). Furthermore, the psychological representation of even meaningless ASL movement forms differs between deaf, native signers and hearing observers unfamiliar with ASL (Poizner, 1981).

Investigation of the perception of sign language using only naturally produced stimuli, however, has some severe limitations. Many psycholinguistic experiments require the precise control over stimulus parameters that only computer-generated sign affords; signers, of course, cannot simply be instructed to produce forms exactly equal in trajectory shape, in movement dynamics, or instructed to produce a series of forms that are separated physically by exactly the same increment, and so forth. The present program, listed in Appendix A, allows the user to computer generate sign forms. The

We thank Ursula Bellugi and James Cutting for their help. This work was supported in part by National Science Foundation Grant BNS79-16423 and National Institutes of Health Grant HD 13249. availability of such computer synthesis of sign could well allow major advances in the experimental investigation of the perception of sign language, much as computergenerated speech has done for the study of speech perception.

\section{HARDWARE AND SOFTWARE}

The program is written in BASIC and implemented on a Hewlett-Packard 9830A microcomputer with an interfaced data tablet (HP-9864A) and $x-y$ plotter (HP-9862A). The program can thus run on readily available and inexpensive microcomputer systems. It is, however, modifiable for other systems. ${ }^{1}$ The program generates a time series of plots of the positions of the joints of the arms and hands for a specified ASL sign. The joints can be connected for a stick-figure representation, or only particular joints themselves can be displayed to synthesize signs as dynamic point-light displays (see Poizner, Bellugi, \& Lutes-Driscoll, 1981).

The program consists of two sets of program modules that have been overlaid to circumvent memory limita. tions of the Hewlett-Packard (7,904 16-bit words of memory). One set of modules (1) sets up an initial skeletal figure (user-specified Operation 1), (2) allows the interactive input, via the data tablet, of functions specifying how joint angles change over time (Operation 3), (3) allows for the storage and retrieval of specified movements (action functions; Operations 5 and 6), and (4) allows for the capability to add two functions together or move a function from one joint angle to another (Operation 7). A second set of program modules takes the skeletal figure description and the digitized action functions and performs the appropriate angular transformations generating a sequence of output plots (Operation 8). The program also provides a spare arm for storage, so that the user can compose a new movement sequence without rebuilding all the time functions.

The heart of the program is the procedure for execut- 


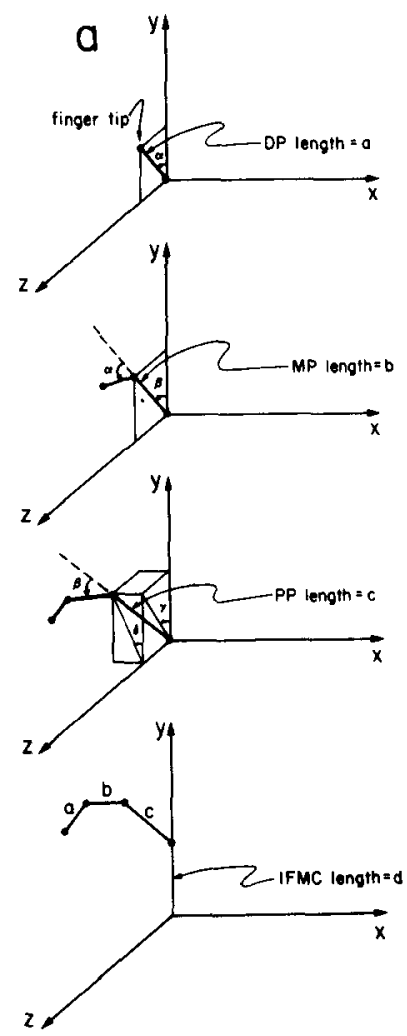

FINGERS

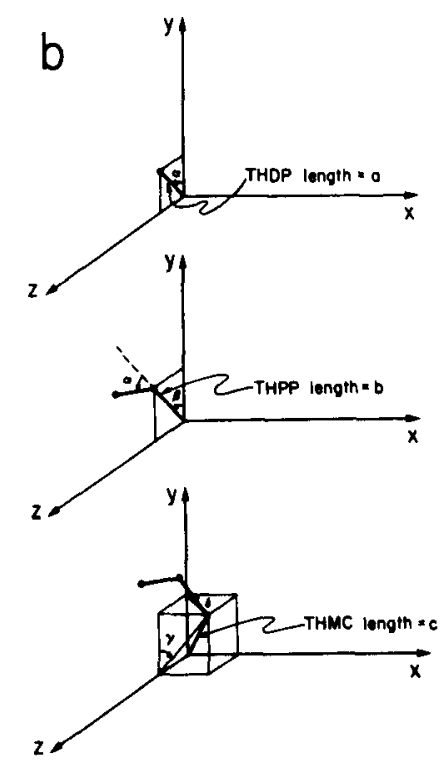

THUMB

Figure 1. Digits of the hand emerging from the origin after successive transformations are applied (a) to the joint angles of the fingers and (b) to the thumb. $\mathrm{PP}=$ proximal phalanx, $\mathrm{MP}=$ middle phalanx, $\mathrm{DP}=$ distal phalanx, MC = metacarpal, $\mathbf{I F}=$ index finger, $T H=$ thumb. See Appendix $C$ for definitions of particular angle function numbers.

ing movements. This procedure involves a sequence of coordinate transformations. Each skeletal point $(x, y$, $z, w)$ is represented in homogeneous coordinates that provide for simple translations of points using 4 by 4 matrix multiplications (see Newman \& Sproull, 1979). Starting with the most distal joints of the arm and hand, a joint is translated to the origin, and a coordinate transformation specified by its angle function (e.g., a particular rotation) is performed on it and on all joints distal to it. That joint and all distal joints are then translated up the $y$-axis so that the next proximal joint goes to the origin. The appropriate coordinate transformation is then applied, and the procedure iterates until the sternum is at the origin. Appendix B provides parameter definitions and default values for skeletal lengths and initial skeletal angles. The user can obtain a desired initial arm and hand configuration by inserting the appropriate angular values in place of the default values listed in Appendix B.

The user specifies an initial configuration for the joint angles (length and joint angle parameter numbers are given in Appendix B) and defines functions that specify how particular joint angles change over time for a given ASL sign (angle number definitions are listed in Appendix C). Figure 1 illustrates digits of the hand emerging from the origin after successive transformations are applied to the joint angles of the fingers (Figure 1a) and to the thumb (Figure 1b). Figure 2 shows the arm and hand emerging from the origin after successive transformations are applied to the joint angles of the wrist (Figure 2a), elbow (Figure 2b), and shoulder (Figure 2c). Plots of the position of the figure for any portion of the movement can then be obtained, with the user specifying beginning and ending times and the step size for time increments.

Figure 3 presents sample output from the program. In Figure $3 b$, four frames of a movement in which the hands pronate (a movement important to ASL) are presented. Figure $3 \mathrm{a}$ shows the plot of how the elbow angle that rotates the forearm (Parameter 23, Appendix C) changes over time, reconstructed by the program from digitized input. The resulting change in the position of the arm over time is shown in successive panels of Figure 3b. Frames 1, 7, 13, and 19 of a 20 -frame sequence are shown, with animation of these frames producing smooth movement. 


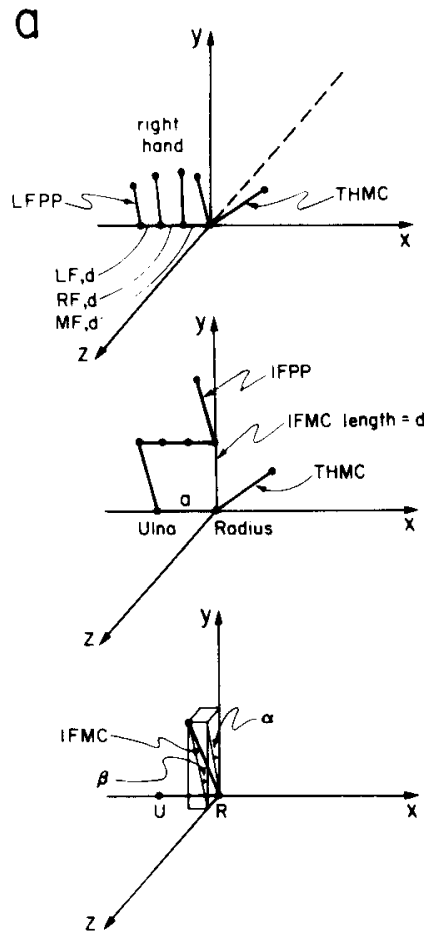

WRIST

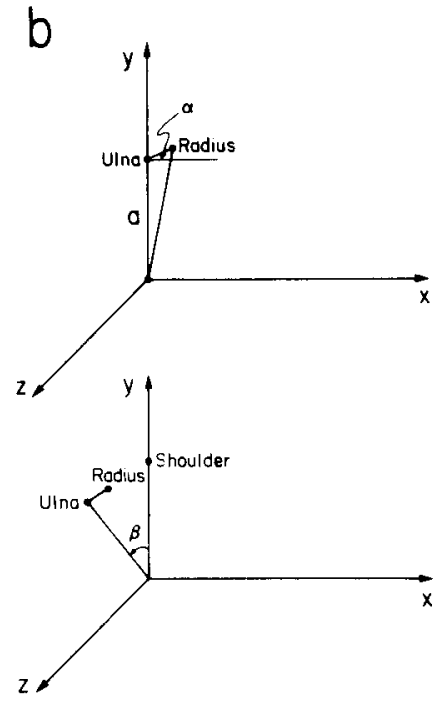

ELBOW

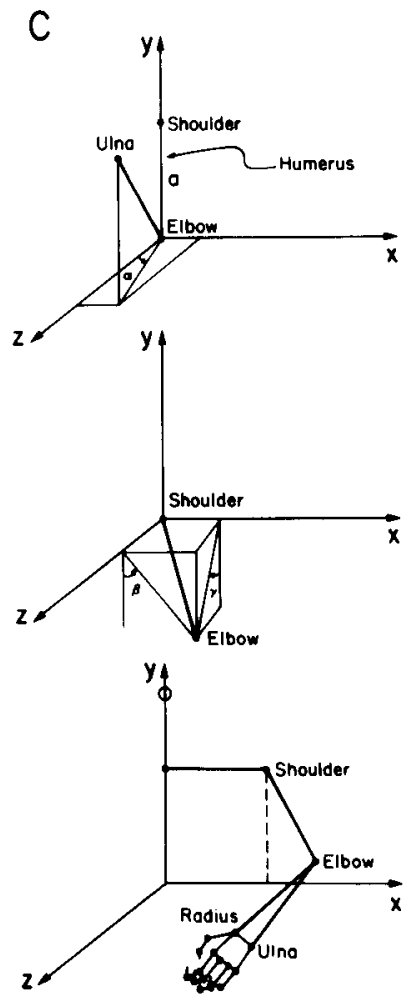

SHOULDER

Figure 2. Arm and hand emerging from the origin after successive transformations are applied to the (a) joint angles of the wrist, (b) elbow, and (c) shoulder. LF = little finger, $R F=$ ring finger, $M F=$ middle finger, $I F=$ index finger. See Appendix $C$ for definitions of particular angle function numbers.
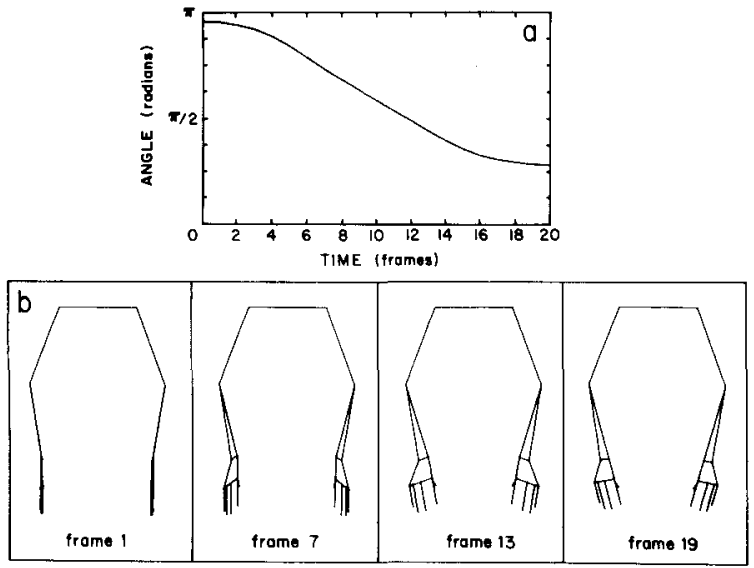

Figure 3. (a) Change in elbow angle over time of joint that rotates the forearm. (b) Four frames of the resulting movement sequence in which the hands pronate.

\section{REFERENCES}

Johansson, G. Visual perception of biological motion and a model for its analysis. Perception \& Psychophysics, 1973, 14, 201-211.
Johansson, G. Visual motion perception. Scientific American, 1975, 232(6), 76-89.

Klima, E. S., \& Bellugi, U. The signs of language. Cambridge, Mass: Harvard University Press, 1979.

Lane, H., \& Grosjean, F. Recent perspectives on American Sign Language. Hillsdale, N.J: Erlbaum, 1980.

Newman, W. N., \& Sprould, R. F. Principles of interactive computer graphics. New York: McGraw-Hill, 1979.

Poizner, H. Visual and "phonetic" coding of movement: Evidence from American Sign Language. Science, 1981, 212, 691. 693.

Poizner, H., Bellugi, U., \& Lutes-Driscoll, V. Perception of American Sign Language in dynamic point-light displays. Journal of Experimental Psychology: Human Perception and Performance, 1981, 7, 430-440.

Poizner, H., Newkirk, D., Bellugi, U., \& Klima, E. S. Representation of inflected signs from American Sign Language in short-term memory. Memory \& Cognition, 1981, 9, 121-131.

\section{NOTE}

1. The program is currently being transferred and extended to run on an Evans and Sutherland Picture System II driven by a PDP-11/34. Information concerning the program is available from Michael Shantz, De Anza Systems, Inc., 118 Sharcot Ave., San Jose, California 95131, and Howard Poizner, Salk Institute for Biological Studies, P.O. Box 85800, San Diego, California 92138. 
Appendix A

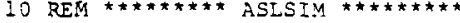

15 REM OPERATION 1 = INITF-INITIALIZE FIGURE

20 REM OPERATION 2 = PLTFIG- PLOT THE FIGURE

25 REM OPERATION 3 = DEFACT- DEFINE ACTION $1-3$

30 REM OPERATION 4 = PLTACT- PLOT ACTION EUNCTION

35 REM OPERATION 5 = SAVACT- SAVE ACTION ON TAPE

40 REM OPERATION 6 = UNSACT- FETCH ACTION FROM TAPE

45 REM OPERATION $7=$ ADDACM- ADD OR MOVE FUNCTIONS

50 REM OPERATION $8=$ DOACT- EXECUTE ACIION ON FIGURE

55 REM -

410 REM * *FIGURE DATA STRUCTURE

500 DIM AS $[150]$, BS $[70,4]$

500 DIM AS $[150]$, BS $[70,4]$
560 REM $* \star \star A C T I O N$ DATA STRUCTURES; 27 DEGREES

570 REM OE FREEDOM FOR EACH ARM, 20 TIME INCREMENTS

580 REM IN AN ACTION

600 DIM IS $[81,20]$

660 REM *** MATRICES AND POINTS

664 DIM LS $[4,4]$, MS $[4,4]$, NS $[4,4]$

568 DIM OS $[4,4]$

670 DIM PS $[1,4]$, QS $[1,4]$

680 DIM RS $[1,4]$, SS $[1,4]$

980 REM GET FUNCTION TO PERFORM 1 INITE, 2PITFIG

982 REM 3 DEFACT, 4 PLTACT, 5 SAVACT, 6 UNSACT, 7 ADDACT,

984 REM 8 DOACT, 9

985 DISP "INITIALIZE FUNCS? L:" :

986 INPUT J

987 IF $J<1$ or $J>1$ THEN 1000

990 FOR $I=1$ TO 31

991 FOR $J=1$ TO 20

$992 I[I, J]=0$

993 NEXT J

994 NEXT I

1000 DISP "ASLSIM OPERATION:" ;

1020 INPUT A

1040 IF A>0 AND A<9 THEN 1200

1080 DISP "SAO FUNCTION"

1090 GOTO 1000

1100 GOSUB A OF $2000,3000,4000,5000,6000,7000,8000,9000$

1200 GOTO 1000

1980 REM **** INITIALIZE EIGURE ***

2000 DISP "DEFAUTT OR MODIFY O/I:";

2012 INPUT I

2014 IF $I=0$ THEN 2050

2016 DISP "ENTER PARAMETER\#, VALUE:" ;

2018 INPUT J,K

$2020 \mathrm{~A}[\mathrm{~J}]=\mathrm{K}$

2030 DISP "ENTER 1 TO QUIT:";

2032 INPUT $\mathrm{X}$

2034 IF $\mathrm{K}=1$ THEN 2190

2036 GOTO 2016

2050 EOR $I=1$ TO 150

$2052 \mathrm{~A}[\mathrm{I}]=0$

2054 NEXT I

2056 FOR $I=1$ TO 70

2058 EOR $J=1$ TO 4

$2060 B[I, J]=0$

2062 NEXT J

$2054 \mathrm{NEXT} I$

2080 REM SEM UP ANGLES OF PHALANGES

$2090 \mathrm{~A}[42]=\mathrm{PI} / 8$

$2092 \mathrm{~A}[44] \times \mathrm{A}[47]=\mathrm{PI} / 4$

2094 A $[48]=3 * 2 I / 8$

2100 FOR $I=1$ TO 4

$2110 \mathrm{~J}=(\mathrm{I}-1) * 10+2$

2112 A [J] $=\mathrm{PI} / 8$

2114 A $[J+2]=A[J+5]=P I / 4$

$2116 \mathrm{~A}[\mathrm{~N}+6]=0$

2118 NEXT I

$2120 \mathrm{~A}[1]=\mathrm{A}[3]=\mathrm{A}[16]=\mathrm{A}[26]=\mathrm{A}[31]=\mathrm{A}[6]=2$

2130 REM SET UP LENGTHS OF HAND BONES

$2132 \mathrm{~A}[5]=4$

$2134 \mathrm{~A}[1]]=\mathrm{A}[21]=2.5$

$2136 A[13]=3.2$

2138 A $[15]=A[25]=A[35]=5$

$2140 A[23]=A[43]=3.5$

$21+2 \mathrm{~A}[33]=\mathrm{A}[41]=3$

$2144 \mathrm{~A}[36]=8$

$2146 \mathrm{~A}[45]=6$

2148 REM SET UP WRIST PARAMS

2150 A [SI] $=5$

$2152 \mathrm{~A}[52]=\mathrm{A}[53]=0$.

2154 REM SET UP ELBOW PARAMS

2156 A $[61]=27$

$2158 \quad[62]=P T / 8$

$2160 \mathrm{~A}[64]=3 * \mathrm{PI} / 4$
2162 REM SET UP SHOULDER PARAIS

2164 A $[67]=30$

$2166 \quad \mathrm{~A}[68]=\mathrm{PI} / 4$

$2168 \mathrm{~A}[69]=\mathrm{A}[70]=0$

2180 FOR $I=1$ TO 70

$2184 \mathrm{~A}[I+75]=\mathrm{A}[\mathrm{I}]$

2186 NEXT I

2190 RFTURN

2995 REM **** PLOT EIGURE ***

3000 DISP "USE DOACT WITH $1,2,1$ ";

3100 WAIT 300

3110 RETURN

3995 REM ****DEFINE ACTION USING DIGITIZER****

3996 REM

4000 DISP "WHICH ACTION, FUNC:" ;

4020 INPUT $X, Y$

4040 IF $x>0$ AND $<4$ AND $Y>0$ AND $Y<28$ THEN 4100

4060 DISP "BAD ACTION OR FUNCTION NO"

4070 WAIT 100

4080 GOTO 4000

4100 WRITE $(9, *)$

$4110 \quad \mathrm{~N}=(\mathrm{X}-1) * 27+\mathrm{Y}$

4200 FOR $\mathrm{T}=1$ TO 20

4210 ENTER $(9, *) P, Q$

$4220 I[W, T]=Q * 0.3927$

4260 IF $P<T / 2.5$ THEN 4210

4265 WRITE $(9, *)$

4270 NEXT T

4300 WRITE $(9, *$

4900 RETURN

4995 REM $\star * \star *$ PLOT ACTION*****

5000 DISP "WHICH ACTION, FUNCTION:"

5020 INPUT $X, Y$

5030 SCALE $-5,25,-P I,+P I$

5040 XAXIS $0,2,0,20$

5050 YAXIS $0, P I / 8,-P I / 2, P I / 2$

5055 PLOT $0,0,1$

$5056 \mathrm{~W}=(\mathrm{X}-1) * 27+Y$

5060 FOR $T=I$ TO 20

5100 PLOT $T, I[W, T], 2$

$5200 \mathrm{NEXT}$

5220 DEN

5240 NRITE $(9, *)$

5900 RETURN

5990 REM ****SAVE ACIION ON TAPE****

6000 DISP "FIIE:";

6010 INPUT $\mathrm{J}$

6035 FIND $J$

6075 STORE DATA J,I

6080 RETURN

6990 REM ****FETCH ACTION FROM TAPE****

7000 DISP "FILE:":

7010 INPUT $\mathrm{J}$

7060 FIND J

7070 LOAD DATA J,I

7120 RETURN

7990 REM ** ADD OR MOVE FUNCTIONS****

8000 DISP "ADO OR MOVE 0/1:"

8010 INPUT C

8014 REM 1 MOVE

8016 DISP "FROM ACI, FUNC, TORCT, FUNC:" ;

8018 INPUT $W, X, Y, Z$

8020 IF $W>0$ AND $N<4$ AND $Y>0$ and $Y<+$ THEN 9030

8022 DISP "ACT $1 / 2 / 3=$ (RIGHT/LEFT/SPARE)"

8023 WAI" 200

8024 GOTO 8016

8030 IF $X>0$ AND $x<28$ AND $z>0$ AND $z<28$ THEN 3040

8032 DISP "VALID FUNCTIONS $1-27$ ";

8033 WAIT 200

8034 GOTO 8016

$8040 \quad I=(W-1) \cdot 27+x$

$8042 \mathrm{~J}=(Y-1) \star 27+2$

8043 IF $C=0$ THEN 8060

8044 FOR K=1 TO 20

$8046 I[J, K]=I[I, K]$

8048 NEXT K

8050 RETURN

8060 REM 2 ADD

8062 FOR $K=1$ TO 20

$8064 I[J, K]=I[J, K]+I[I, K]$

8066 NEXT K

8070 RETURN

8990 REM ****EXECUTE AN ACTION ON THE FIGURE

9000 LINK 2

9100 END 
10 REM $\star * \star * \star * * *$ ASLSIM; ASLACT $* * * * * * * * * * *$

20 REM THIS OPERATION EXECUTES AN ACTION ON THE FIGURE 410 REM **FIGURE DATA STRUCTURE

420 REM POINTS AND POSITIONS

500 REM AS $(150), B S(70,4)$

560 REM $* * \star *$ ACTION DATA STRUCTURES: 27 DEGREES

570 REM OE FREEDOM FOR EACH ARM, 20 TIME INCREMENTS

580 REM IN AN ACTION

600 REM IS $(81,20)$

660 REM ***MATRICES AND POIN"S

$664 \operatorname{REM} \operatorname{LS}(4,4), \mathrm{MS}(4,4), \mathrm{NS}(4,4)$

$668 \mathrm{REM}$ OS $(4,4)$

670 REM PS $(1,4)$, QS $(1,4)$

$680 \operatorname{REM} R S(1,4), \operatorname{SS}(1,4)$

1000 GOTO 8990

2300 REH SUBROUTINE TO TRANSFORM POINTS

2310 FOR $z=G$ TO $\mathrm{H}$

2312 FOR $W=1$ TO 4

$2314 P[1, W]=B[2, W]$

2316 NEXT $W$

$2318 \mathrm{MAT} Q=P^{*} M$

2320 EOR $W=1$ TO 4

$2322 B[Z, W]=Q[1, W]$

2324 NEXT $W$

$2350 \mathrm{NEXT} Z$

2352 RETURN

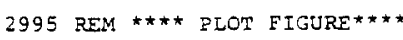

3000 SCALE $-100,+100,-50,+50$

3100 OFFSEM 0,0

3102 REM 1 PLOT THE SHOULDER, ELBOW, WRIST

$3110 \quad \mathrm{~N}=0$

3112 PLOT $0,20,1$

$3114 \mathrm{~S}=\mathrm{W}+34$

3116 PLOT $\mathrm{B}[S, 1], 3[S, 2], 2$

$3118 \mathrm{~S}=\mathrm{W}+31$

3120 PLOT B $[5,1], B[S, 2], 2$

$3122 \mathrm{~S}=\mathrm{W}+27$

3124 PLOT $B[S, 1], B[S, 2], 2$

$3126 \mathrm{~S}=\mathrm{W}+26$

3128 PLOT B [S, 1], B [S, 2], 2

$3130 \quad \mathrm{~s}=\mathrm{W}+31$

3132 PLOT $B[S, 1], B[S, 2], 2$

$3134 \mathrm{~S}=\mathrm{W}+27$

3136 PLOT $B[S, 1], B[S, 2\}, 1$

$3138 \mathrm{~S}=\mathrm{W}+4$

3240 PLOT $B[S, 1], B[S, 2], 2$

3150 REM 2 FLOT THE FINGERS

3152 IOR $z=1$ TO 16 STEP 5

$3154 \mathrm{~S}=\mathrm{W}+2$

3156 PLOT $B[S, 1], B[S, 2], 1$

3158 FOR $R=1$ TO 3

$3160 \mathrm{~S}=\mathrm{S}+1$

$3] 62$ PIOT $B[S, 1], B[S, 2], 2$

3164 NEXT R

3166 NEXr 2

3180 REM 3 PLOT THE PALM AND THE THUMB

$3182 \mathrm{~S}=\mathrm{W}+4$

3184 PLOT B $[S, 1], B[5,2 !]$

$3186 \mathrm{~S}=\mathrm{W}+19$

3188 PLOT $B[S, 1], 3[S, 2], 2$

$3190 \quad \mathrm{~S}=\mathrm{W}+23$

3192 शLOT B:S,1],B[S,2:,2

$3194 \mathrm{~S}=\mathrm{W}+26$

3196 PIOT B $[S, 1], B[S, 2\}, 2$
$3198 \mathrm{~S}=\mathrm{W}+2$ ?

3200 PLOT $3[5,1], 3[5,2], 1$

$3202 S=N+22$

3204 PLOT 3 is, 1], B[S, 2],2

$3206 \mathrm{~s}=\mathrm{w}+23$

3208 PLOT 3 is, 1;,B[S, 2 : ,

3210 IF $N>0$ THEN 3230

$3220 \quad \mathrm{~N}=35$

3222 GoTO $32: 2$

$3230 \geq F \mathrm{~N}$

3240 RETURN

8990 REM ***EXECUTE AN ACTION ON THE FIGURE

9000 DISP "TIME T1,T2,TSTEP:";

9010 INPUT T, U, V

9020 IE T>0 AND T<U AND U<21 THEN 9050

9030 DISP "BAD TIME SEGMENT."

9040 WAIT 200

9045 GOTO 9000

9049 REM FOR ALL TIME STEPS,L=IDENTITY MATRIX, ...

9050 FOR I=T TO U STEP $V$

9052 FOR $\mathrm{J}=1$ TO 70

$\pm 054 \mathrm{~B}[\mathrm{~J}, 1]=\mathrm{B}[\mathrm{J}, 2]=\mathrm{B}[\mathrm{J}, 3]=0$

$9056 B[J, 4]=1$

9058 NEXT $J$

9050 EOR $J=1$ TO 4

$9070 \quad E O R \quad K=1$ TO 4

$9080 \mathrm{~L}[\mathrm{~J}, \mathrm{~K}]=1$

9090 IF $J=K$ TEEN 9200

$9094 \mathrm{~L}[\mathrm{~J}, \mathrm{~K}]=0$

$9100 \mathrm{NEXT} K$

9120 NEXT J

9119 SEM SET TO DO RIGHT ARM, LITTLE FINGER

$9120 \quad E=E=0$

$9122 \mathrm{C}=0$

$9124 x=-1$

$9126 \mathrm{~s}=0$

9129 REM 1 TRANSIATE DISTAL PHALANX UP Y AXIS

$9130 \mathrm{~J}=\mathrm{E}+1$

$9132 \mathrm{~K}=\mathrm{F}+\mathrm{I}$

$9133 \mathrm{D}=\mathrm{C}+\mathrm{i}$

$9134 B[\mathrm{~J}, 1 ;=B[J, 3]=0$

9136 B $[J, 2]=\mathrm{A}[\mathrm{K}]$

$9138 B[U, 4]=1$

9140 REM 2 ROTATE OISTAL PHALANX ALPHA ABOUT $X$ AXTS

$9 \mathrm{I}+2 \mathrm{~K}=\mathrm{K}+1$

9144 MAT $M=L$

$9146 M[2,2]=M[3,3]=\cos (A[K]+I[0, I]:$

$91+8 \quad M[2,3]=\sin (A[K)+I[D, I\})$

$9130 M[3, z]=-M[2,3]$

$9152 \mathrm{G}=\mathrm{H}=\mathrm{I}$

9156 GOSLB 2300

9160 REM 3 TRANSILATE MIDDLE PHALANX UP $Y$ AXIS AND

9162 REM ROTATE BETA ABOUT $X$ AXIS

$9164 \mathrm{~K}=\mathrm{K}+\mathrm{I}$

9166 MAT N=L

$9168 \mathrm{~N}[4,2]=\mathrm{A}[\mathrm{K}]$

9170 MAT $0=1$

$9172 \mathrm{k}=\mathrm{k}+1$

$9173 \mathrm{D}=\mathrm{D}+\mathrm{L}$

$9174 O[2,2]=O[3,3]=\cos (A[K]+I[D, I])$

$9175 O[2,3]=\operatorname{SIN}(A[K]+I[D, I])$

$91780[3,2]=-O[2,3]$

9180 MAT $M=N * O$

$9182 \mathrm{H}=\mathrm{H}+\mathrm{l}$ 
9184 GOSUB 2300

9190 REM 4 TRANSLATE PROXIMAL PHALANX $C$ UP $Y$ AXIS,

9192 REM ROTATE GAMMA ABOUT $X$ AND DELTA ABOUT 2

$9194 \mathrm{~K}=\mathrm{K}+1$

9196 MAT M=L

$9198 M[4,2]=A[R]$

$9200 \quad \mathrm{~K}=\mathrm{K}+2$

$9201 D=D+1$

9202 MAT N=L

$9204 N[2,2]=N[3,3]=\operatorname{Cos}(A[K]+I[D, I])$

$9206 N[2,3]=\operatorname{SIN}(A[K]+I(D, I])$

$9208 N[3,2]=-N[2,3]$

9210 MAT $O=M * N$

$9212 \mathrm{~K}=\mathrm{K}+1$

$9213 \mathrm{D}=\mathrm{D}+1$

9214 MAT N=L

$9216 \mathrm{~N}[1,1]=\mathrm{N}[2,2]=\operatorname{COS}(\mathrm{A}[\mathrm{K}]+I[D, I])$

$9218 \mathrm{~N}[1,2]=\operatorname{SIN}(A[K]+I[D, I])$

$9220 \mathrm{~N}[2,1]=-\mathrm{N}[1,2]$

9222 MAT $M=O * N$

$9224 \mathrm{H}=\mathrm{H}+1$

9226 GOSUB 2300

9240 REM 5 REPEAT THE ABOVE FOR ALL FINGERS

9250 IF $(\mathrm{J}-\mathrm{E})>12$ THEN 9300

$9252 \mathrm{~J}=\mathrm{J}+5$

$9254 \mathrm{~K}=\mathrm{K}+3$

$9256 \mathrm{D}=\mathrm{D}+1$

9258 GOTO 9134

9300 REM 6 TRANSLATE THUMB OISTAL PHALANX UP Y AXIS,

9302 REM ROTATE ALPHA ABOUT X AXIS.

$9304 \mathrm{~J}=\mathrm{E}+21$

$9306 \mathrm{~K}=\mathrm{F}+41$

$9307 \quad D=C+17$

9308 MAT $N=L$

$9310 N[4,2]=A[K]$

$9312 \mathrm{~K}=\mathrm{K}+1$

9314 MAT O=L

$9316 O[2,2]=O[3,3]=\cos (A[K]+I[D, I])$

$9318 O[2,3]=S I N(A[K]+I[D, I])$

$9320 O[3,2]=-O[2,3]$

9322 MAT $M=N * O$

$9324 \mathrm{G}=\mathrm{H}=\mathrm{J}$

9326 GOSUB 2300

9340 REM 7 TRANSLATE THUMB RROXIMAL PHALANX B UP Y AXIS,

9342 REM ROTATE BETA ABOUT $X$ AXIS.

$9344 K=K+1$

$9345 \mathrm{D}=\mathrm{C}+18$

9346 MAT $N=L$

$9348 N[4,2]=A[K]$

$9350 \mathrm{~K}=\mathrm{K}+1$

9352 MAT $O=L$

$9354 O[2,2]=O[3,3]=\operatorname{Cos}(A[K]+I[D, I])$

$9356 O[2,3]=\operatorname{SIN}(A[K]+I[D, I])$

$93580[3,2]=-0[2,3]$

9360 MAT $M=N * 0$

$9362 \mathrm{H}=\mathrm{H}+1$

9364 GOSUB 2300

9390 REM 8 TRANSIATE THUMB METACARPAL UP $Y$,

9382 REM ROTATE GAMMA ABOUT 2 .

9386 REM ROTATE DELTA ABOUT $Y$

$9388 \mathrm{~K}=\mathrm{K}+1$

9390 MAT $M=L$

$9392 M[4,2]=A[K]$

$9394 K=K+2$

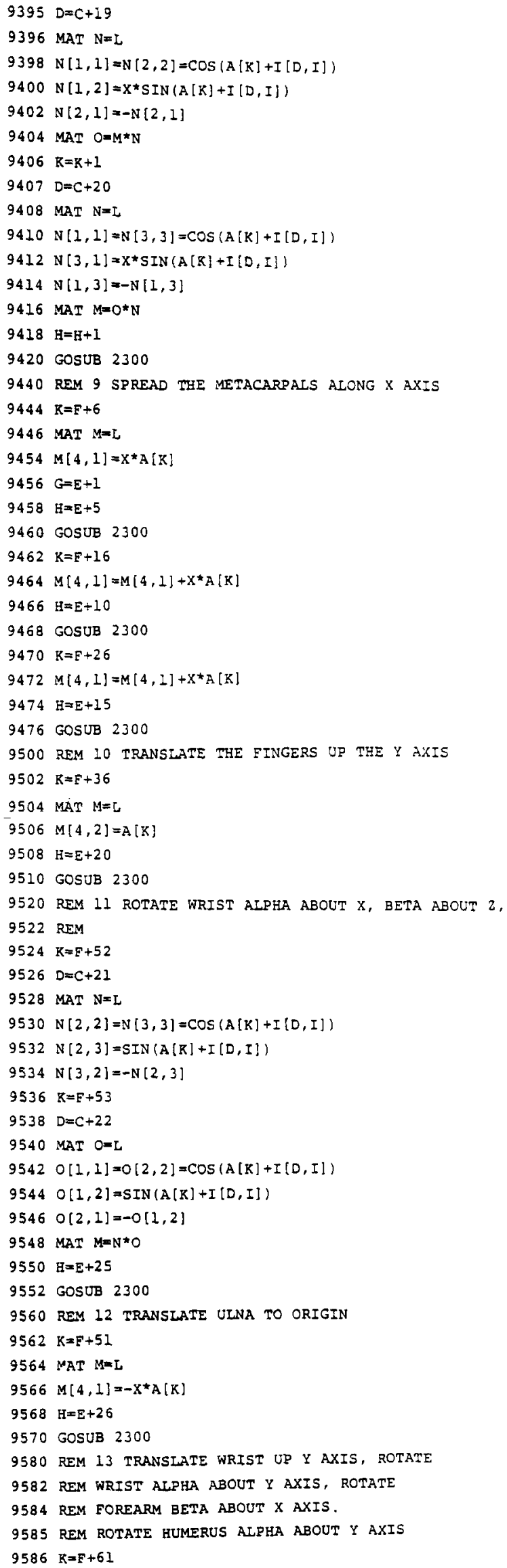




\begin{tabular}{|c|c|c|c|}
\hline \multirow[b]{2}{*}{ Parameter Description } & \multicolumn{2}{|c|}{ Parameter Number } & \multirow{2}{*}{$\begin{array}{l}\text { Default } \\
\text { Value* }\end{array}$} \\
\hline & Right Arm & Left Arm & \\
\hline \multicolumn{4}{|l|}{ Index Finger (if) } \\
\hline length ifdp a & 31 & 106 & 2 \\
\hline angle ifdp alpha (flexion and extension) & 32 & 107 & $\mathrm{pi} / 8$ \\
\hline length ifmp b & 33 & 108 & 3 \\
\hline angle ifmp beta (flexion and extension) & 34 & 109 & $\mathrm{pi} / 4$ \\
\hline length ifpp $c$ & 35 & 110 & 5 \\
\hline length ifmc $d$ & 36 & 111 & 8 \\
\hline angle ifpp gamma (flexion and extension) & 37 & 112 & $\mathrm{pi} / 4$ \\
\hline angle ifpp delta (abduction and adduction) & 38 & 113 & 0 \\
\hline \multicolumn{4}{|l|}{ Thumb (th) } \\
\hline length thdp a & 41 & 116 & 3 \\
\hline angle thdp alpha (flexion and extension) & 42 & 117 & $\mathrm{pi} / 8$ \\
\hline length thpp b & 43 & 118 & 3.5 \\
\hline angle thpp beta (flexion and extension) & 44 & 119 & $\mathrm{pi} / 4$ \\
\hline length thme $\mathrm{c}$ & 45 & 120 & 6 \\
\hline angle thmc gamma (flexion and extension) & 47 & 122 & $\mathrm{pi} / 4$ \\
\hline angle thme delta (abduction and adduction) & 48 & 123 & $3 \mathrm{pi} / 8$ \\
\hline \multicolumn{4}{|l|}{ Wrist } \\
\hline width a & 51 & 126 & 5 \\
\hline angle (palmar) alpha (flexion and extension) & 52 & 127 & 0 \\
\hline angle (sideways) beta (radial and ulnar deviation) & 53 & 128 & $\mathbf{0}$ \\
\hline \multicolumn{4}{|l|}{ Elbow } \\
\hline length ulna a & 61 & 136 & 27 \\
\hline pronation and supination angle (rotate forearm) alpha & 62 & 137 & $\mathrm{pi} / 8$ \\
\hline flexion and extension angle beta & 64 & 139 & $3 \mathrm{pi} / 4$ \\
\hline \multicolumn{4}{|l|}{ Shoulder } \\
\hline length humerus a & 67 & 142 & 30 \\
\hline rotation angle (about humerus) alpha & 68 & 143 & $\mathrm{pi} / 4$ \\
\hline angle (outward) beta (abduction and adduction) & 69 & 144 & 0 \\
\hline angle (forward) gamma (flexion and extension) & 70 & 145 & 0 \\
\hline
\end{tabular}

* $l$ ngths in centimeters; angles in radians.

Appendix $\mathbf{C}$

Angle Function Definitions for Creating Movements

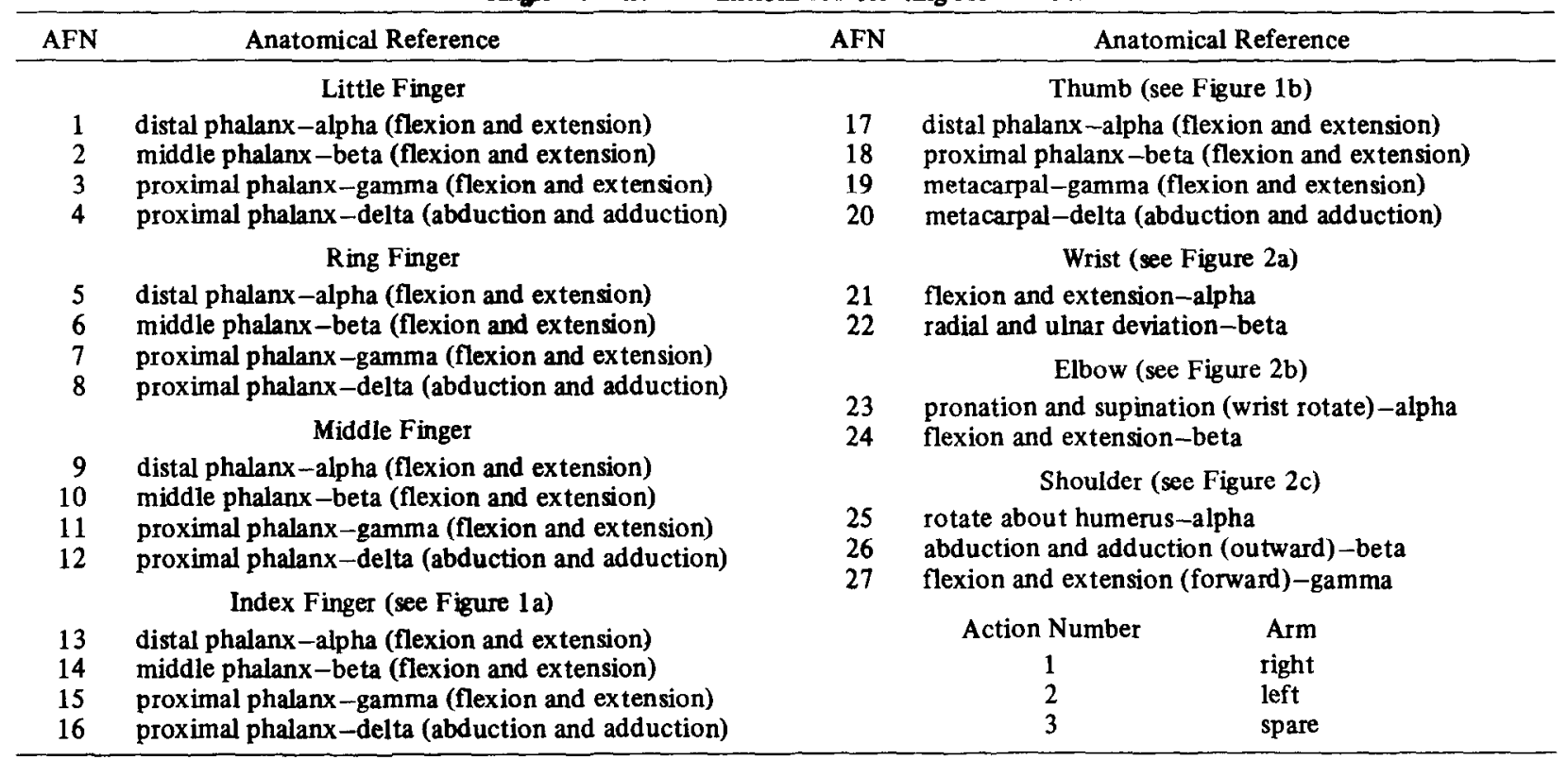

Note-AFN = angle function number. 